\title{
Correction: Comparative analysis of fungal genomes reveals different plant cell wall degrading capacity in fungi
}

\author{
Zhongtao Zhao ${ }^{1}$, Huiquan Liu ${ }^{1 *}$, Chenfang Wang ${ }^{1}$ and Jin-Rong $\mathrm{Xu}^{1,2}$
}

\begin{abstract}
The version of this article published in BMC Genomics 2013, 14: 274, contains 9 unpublished genomes (Botryobasidium botryosum, Gymnopus luxurians, Hypholoma sublateritium, Jaapia argillacea, Hebeloma cylindrosporum, Conidiobolus coronatus, Laccaria amethystina, Paxillus involutus, and P. rubicundulus) downloaded from JGI website. In this correction, we removed these genomes after discussion with editors and data producers whom we should have contacted before downloading these genomes. Removing these data did not alter the principle results and conclusions of our original work. The relevant Figures 1, 2, 3, 4 and 6; and Table 1 have been revised. Additional files 1, 3,4 , and 5 were also revised. We would like to apologize for any confusion or inconvenience this may have caused.
\end{abstract}

Background: Fungi produce a variety of carbohydrate activity enzymes (CAZymes) for the degradation of plant polysaccharide materials to facilitate infection and/or gain nutrition. Identifying and comparing CAZymes from fungi with different nutritional modes or infection mechanisms may provide information for better understanding of their life styles and infection models. To date, over hundreds of fungal genomes are publicly available. However, a systematic comparative analysis of fungal CAZymes across the entire fungal kingdom has not been reported.

Results: In this study, we systemically identified glycoside hydrolases (GHs), polysaccharide lyases (PLs), carbohydrate esterases (CEs), and glycosyltransferases (GTs) as well as carbohydrate-binding modules (CBMs) in the predicted proteomes of 94 representative fungi from Ascomycota, Basidiomycota, Chytridiomycota, and Zygomycota. Comparative analysis of these CAZymes that play major roles in plant polysaccharide degradation revealed that fungi exhibit tremendous diversity in the number and variety of CAZymes. Among them, some families of GHs and CEs are the most prevalent CAZymes that are distributed in all of the fungi analyzed. Importantly, cellulases of some GH families are present in fungi that are not known to have cellulose-degrading ability. In addition, our results also showed that in general, plant pathogenic fungi have the highest number of CAZymes. Biotrophic fungi tend to have fewer CAZymes than necrotrophic and hemibiotrophic fungi. Pathogens of dicots often contain more pectinases than fungi infecting monocots. Interestingly, besides yeasts, many saprophytic fungi that are highly active in degrading plant biomass contain fewer CAZymes than plant pathogenic fungi. Furthermore, analysis of the gene expression profile of the wheat scab fungus Fusarium graminearum revealed that most of the CAZyme genes related to cell wall degradation were up-regulated during plant infection. Phylogenetic analysis also revealed a complex history of lineage-specific expansions and attritions for the PL1 family.

Conclusions: Our study provides insights into the variety and expansion of fungal CAZyme classes and revealed the relationship of CAZyme size and diversity with their nutritional strategy and host specificity.

Keywords: Fungi, CAZymes, Glycoside hydrolase, Polysaccharide lyase, Carbohydrate esterase, Pectinase, Cutinase, Lignocellulase

\footnotetext{
* Correspondence: liuhuiquan@nwsuaf.edu.cn

${ }^{1}$ NWAFU-PU Joint Research Center and State Key Laboratory of Crop Stress Biology for Arid Areas, College of Plant Protection, Northwest A\&F University, Yangling, Shaanxi 712100, China

Full list of author information is available at the end of the article
}

\section{Biomed Central}

(c) 2013 Zhao et al.; licensee BioMed Central Ltd. This is an open access article distributed under the terms of the Creative Commons Attribution License (http://creativecommons.org/licenses/by/2.0), which permits unrestricted use, distribution, and reproduction in any medium, provided the original work is properly cited. 


\section{Background}

This article has been published as a correction for [1]. After discussion with the data producers and journal editors, we removed 9 unpublished genomes from our analysis (Botryobasidium botryosum, Gymnopus luxurians, Hypholoma sublateritium, Jaapia argillacea, Hebeloma cylindrosporum, Conidiobolus coronatus, Laccaria amethystina, Paxillus involutus, and P. rubicundulus). The main conclusions of our work remain unchanged. We apologize for any inconvenience.

Carbohydrate-active enzymes (CAZymes) are responsible for the breakdown, biosynthesis or modification of glycoconjugates, oligo- and polysaccharides. Most importantly, the CAZymes produced by parasites play a central role in the synthesis and breakdown of plant cell wall as well as in host-pathogen interactions [2]. At present, the CAZymes have been grouped into four functional classes: glycoside hydrolases (GHs), glycosyltransferases (GTs), polysaccharide lyases (PLs), and carbohydrate esterases (CEs) based on their structurally-related catalytic modules or functional domains [2]. Among them, the CAZymes of classes $\mathrm{CE}, \mathrm{GH}$, and PL are often known as cell wall degrading enzymes (CWDEs) due to their important roles in plant biomass decomposition by fungi and bacteria [3]. In addition to the catalytic modules, around 7\% of CAZymes also contain the carbohydrate-binding modules (CBMs), which are the most common noncatalytic modules associated with enzymes active in cellwall hydrolysis [2].

Fungi can produce all kinds of CAZymes $[2,4]$. Among them, plant cell wall degrading enzymes received special attentions because of their importance in fungal pathogens for penetration and successful infection of their hosts. Carbohydrates released from plant cell wall also can supply nutrition for fungal growth. As a matter of fact, some saprophytic fungi obtain nutrition for growth and reproduction mainly by degrading plant cell wall materials with a variety of CWDEs. A number of studies have revealed that activities of hydrolytic enzymes from different fungi showed preferences for different types of plant biomass and adaption to their lifestyles $[5,6]$. When cultured on different substrates, various plant biomass degrading enzymes were shown to be produced by different fungi, including the model filamentous fungus Neurospora crassa [7-13]. The white-rot basidiomycete fungi such as Phanerochaete chrysosporium are found to be the main producers of ligninases for substantial lignin decay in wood $[14,15]$. For fungal pathogens, localized degradation of cell wall is necessary for accessing plant cytoplasm and spreading across host tissues. In several plant pathogenic fungi, CWDEs such as pectinases and xylanases were demonstrated to be related to pathogenicity or virulence [16-18].
To date, over a hundred of fungal genomes have been sequenced and are publicly available, including representative fungi from Ascomycota, Basidiomycota, Zygomycota, and Chytridiomycota. Most of fungi except Saccharomycetes and Schizosaccharomycetes have a large number of CWDE genes that are likely involved in plant infection or survival in the environments. Some genes coding polysaccharide degrading enzymes have expanded family members in certain fungi and gene redundancy has been shown to guard critical functions [19]. However, a complete and systematic comparative analysis of CAZymes across the fungal kingdom has not been reported. In addition, it is still unclear whether the distribution of CAZymes in fungi is related to the plant cell wall components, although plant cell walls of dicots and monocot are known to be composed of different components particularly on pectins and hemicelluloses $[6,20,21]$.

In this study, we identified and compared the full repertoires of CAZymes from representative fungi and performed a comprehensive comparison upon the distribution and abundance of CAZyme families to obtain clues to their digestive potential, especially against plant cell wall polysaccharides. Differences in the number and variety of CAZymes among saprophytic, facultative parasitic, hemibiotrophic, biotrophic, and symbiotic fungi were analyzed. The relationship between the number and variety of CAZymes and fungal nutritional strategy and host specificity was also examined.

\section{Results and discussion}

\section{The distribution of CAZyme families}

The predicted proteomes of 94 fungi from Ascomycota, Basidiomycota, Chytridiomycota, and Zygomycota were systematically screened for different families of CAZymes and CBMs based on family-specific HMMs [22]. These fungi represent five types of nutritional mode, saprophytic, facultative parasitic, hemi-biotrophic, biotrophic, and symbiotic fungi, and include pathogens of plants, vertebrates, nematodes, and insects.

In total, 186 CAZyme families were identified in fungal predicted proteomes. Over a half of the fungi analyzed contain more than 300 CAZymes (Figure 1; Additional file 1). Note that the 'CAZymes' referred here and below indicates functional modules or domains not genes unless otherwise specified. Some CAZyme families, such as CE1, GH5, GH47, and GT2, were detected in all the fungal species examined (Figure 2), while some others, such as CE13, GH104, GH42, and GH77, occurred only in a few fungi (Enzymatic activities are listed in Additional file 2). Interestingly, the distribution of some CAZyme families appeared to be phylum-specific. For example, 28 families, including GH130, GH67, GH94, PL10, and PL11, were only found in the Ascomycetes. In contrast, 


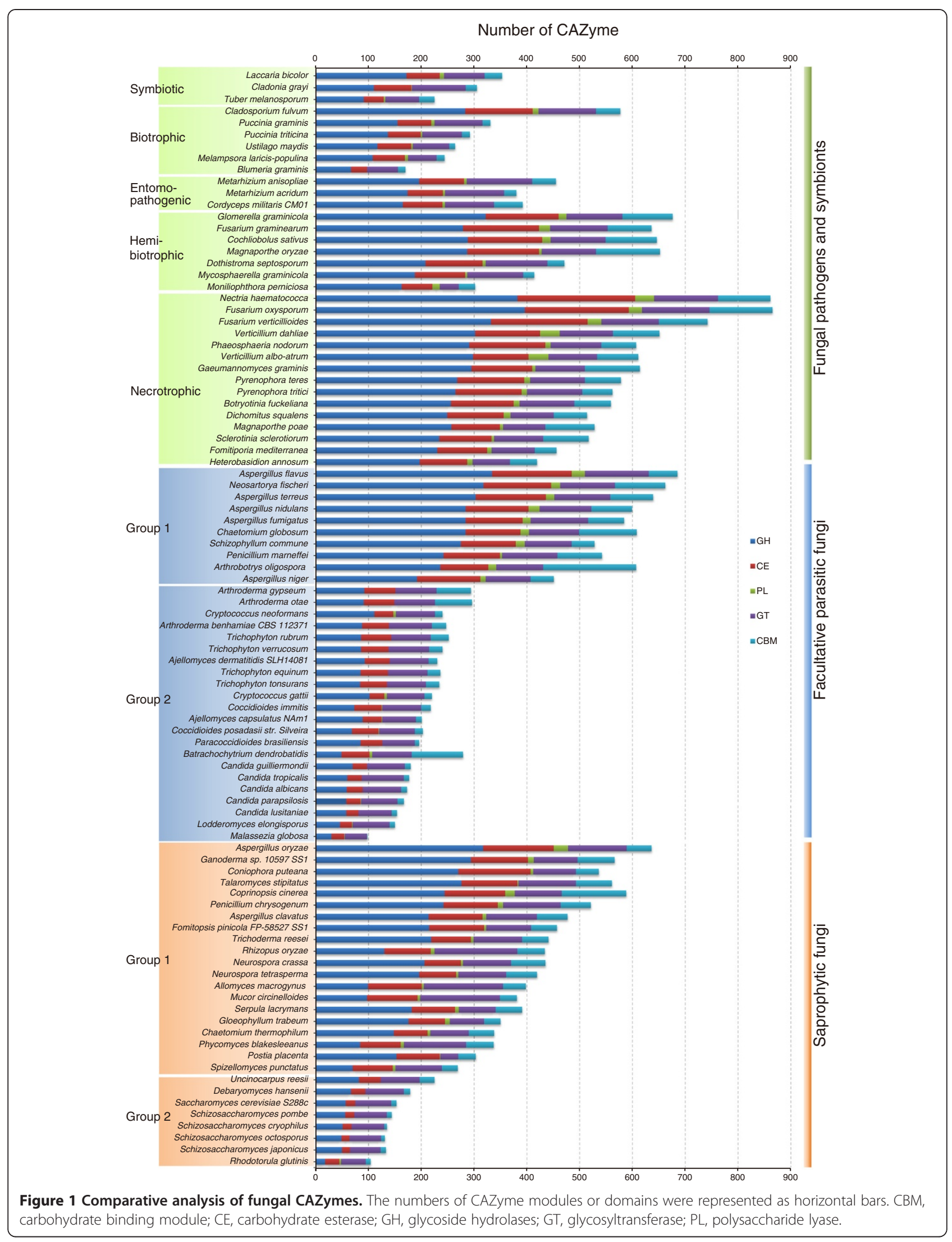




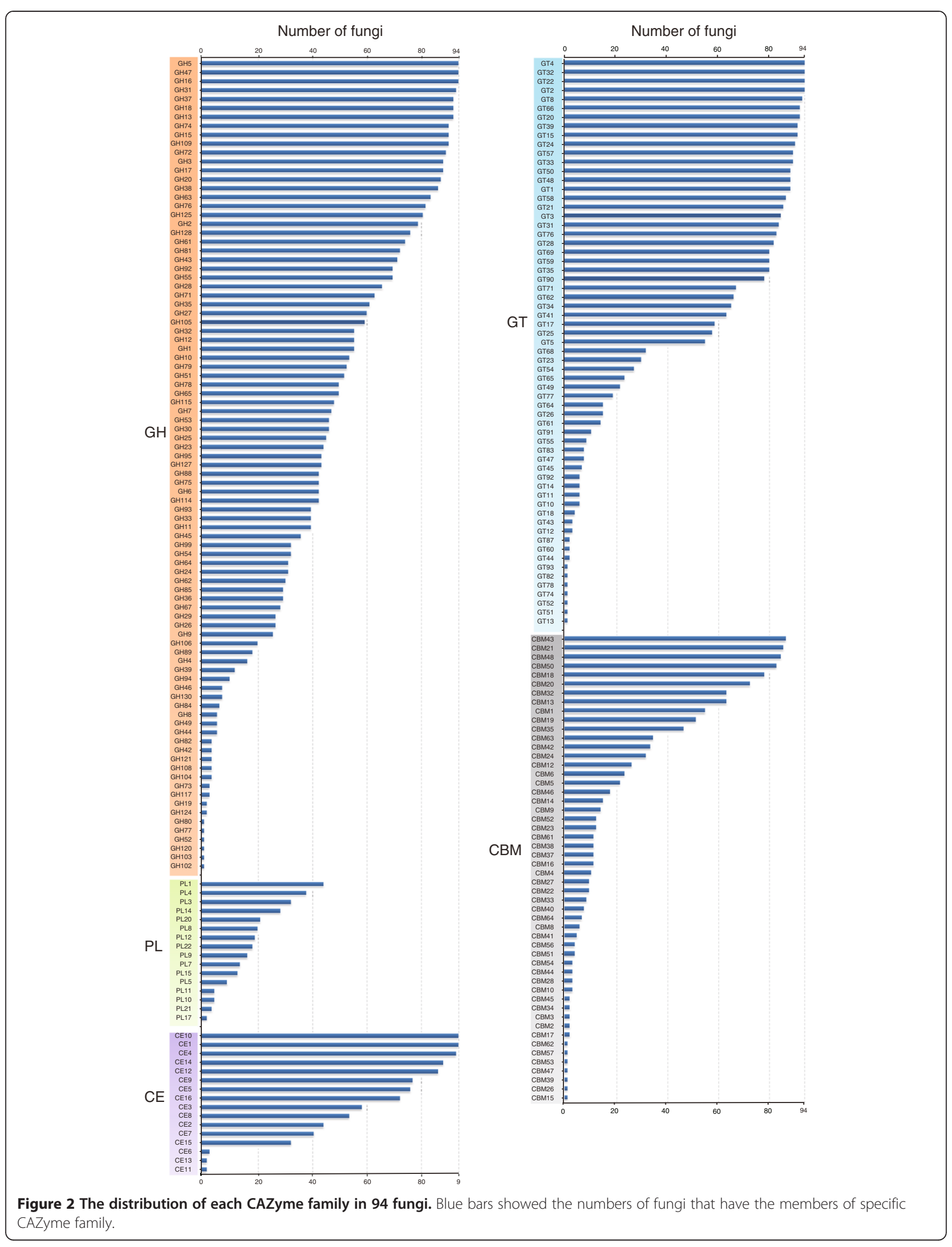


14 families, including GH44 and PL15, appeared to be Basidiomycota-specific (Table 1).

\section{Glycoside hydrolases (GHs)}

GHs hydrolyze the glycosidic bond between two or more carbohydrates, or between a carbohydrate and a noncarbohydrate moiety, such as a protein, or a lipid [2]. To date, GHs are grouped into 127 families based on amino acid sequence in the CAZy database. Among the 127 families, 91 of them were detected in fungi examined, with the most prevalent families being GH5, GH13, GH31, and GH61 (Figure 2). Our results showed that $\mathrm{GH}$ families vary distinctly on distribution and abundance in fungi (Figure 2). For example, numerous members of families GH16 and GH18 are present in all fungi examined and 92 fungi, respectively. For families GH73, GH77, and GH104, only a single member each was identified in one predicted proteome (Figure 2). Interestingly, only the entomopathogenic fungus Cordyceps militaris has one member of family GH19, which is expanded in plants and bacteria [2,23]. Ascomycetes and Basidiomycetes

Table 1 Phylum specific CAZyme and CBM families

\begin{tabular}{|c|c|c|c|c|c|c|c|c|c|}
\hline Family & $A$ & $B$ & $Z$ & $C$ & Family & $A$ & $B$ & $Z$ & $C$ \\
\hline CBM15 & 0 & 0 & 1 & 0 & $\mathrm{GH} 44$ & 0 & 3 & 0 & 0 \\
\hline CBM16 & 12 & 0 & 0 & 0 & GH49 & 6 & 0 & 0 & 0 \\
\hline CBM23 & 13 & 0 & 0 & 0 & GH52 & 0 & 0 & 1 & 0 \\
\hline CBM26 & 1 & 0 & 0 & 0 & $\mathrm{GH} 67$ & 31 & 0 & 0 & 0 \\
\hline CBM27 & 10 & 0 & 0 & 0 & GH77 & 0 & 0 & 0 & 1 \\
\hline CBM28 & 3 & 0 & 0 & 0 & GH80 & 0 & 1 & 0 & 0 \\
\hline CBM37 & 12 & 0 & 0 & 0 & GH82 & 4 & 0 & 0 & 0 \\
\hline CBM39 & 0 & 1 & 0 & 0 & GH94 & 11 & 0 & 0 & 0 \\
\hline CBM44 & 3 & 0 & 0 & 0 & GT13 & 0 & 1 & 0 & 0 \\
\hline CBM47 & 0 & 1 & 0 & 0 & GT18 & 0 & 3 & 0 & 0 \\
\hline CBM53 & 0 & 0 & 0 & 1 & GT43 & 0 & 3 & 0 & 0 \\
\hline CBM57 & 1 & 0 & 0 & 0 & GT51 & 1 & 0 & 0 & 0 \\
\hline CBM62 & 1 & 0 & 0 & 0 & GT52 & 0 & 1 & 0 & 0 \\
\hline CBM8 & 0 & 2 & 0 & 0 & GT54 & 29 & 0 & 0 & 0 \\
\hline CBM9 & 15 & 0 & 0 & 0 & GT55 & 9 & 0 & 0 & 0 \\
\hline CE11 & 2 & 0 & 0 & 0 & GT74 & 0 & 1 & 0 & 0 \\
\hline CE6 & 0 & 0 & 3 & 0 & GT78 & 1 & 0 & 0 & 0 \\
\hline GH102 & 0 & 1 & 0 & 0 & GT82 & 1 & 0 & 0 & 0 \\
\hline GH103 & 1 & 0 & 0 & 0 & GT93 & 0 & 1 & 0 & 0 \\
\hline GH117 & 3 & 0 & 0 & 0 & PL10 & 5 & 0 & 0 & 0 \\
\hline GH120 & 1 & 0 & 0 & 0 & PL11 & 5 & 0 & 0 & 0 \\
\hline GH121 & 4 & 0 & 0 & 0 & PL15 & 0 & 10 & 0 & 0 \\
\hline GH124 & 0 & 1 & 0 & 0 & PL17 & 2 & 0 & 0 & 0 \\
\hline GH130 & 8 & 0 & 0 & 0 & & & & & \\
\hline
\end{tabular}

Digits refer to the number of fungi which have enzymes in specific family. A, Ascomycota; B, Basidiomycota; Z, Zygomycota; C, Chytridiomycota. differ in the abundance of some families. For instance, Ascomycetes have more members of families $\mathrm{GH} 2$ (independent samples $t$ test, $\mathrm{P}<0.01)$, GH72 $(\mathrm{P}<0.01)$, and GH76 $(\mathrm{P}<0.01)$ but fewer members of families GH5 $(\mathrm{P}<0.01)$ and GH79 $(\mathrm{P}<0.01)$ (Figure 3$)$ than Basidiomycetes.

\section{Polysaccharide Lyases (PLs)}

PLs mainly degrade glycosaminoglycans and pectin $[2,24]$. They are classified into 21 families in CAZy database. Our results showed that fungi encode $16 \mathrm{PL}$ families, with the most populated family being PL1 (Figure 2). Ascomycetes and Basidiomycetes have no obvious differences in the number of PLs. However, families PL10, PL11, and PL17 are Ascomycota-specific although they are present only in few Ascomycetes. Family PL15 is specific to Basidiomycota (Table 1). Among the 94 fungi examined, 21 lack any PL. The majority of them are saprophytic or facultative parasitic, such as yeasts and fungi in genus Trichophyton. The biotrophic barley powdery mildew fungus Blumeria graminis is the only plant pathogenic fungus that lacks any PL.

\section{Carbohydrate esterases (CEs)}

CEs catalyze the de-O or de-N-acylation of esters or amides and other substituted saccharides in which sugars play the role of alcohol and amine [25]. Our results showed that fungi have 15 of the $16 \mathrm{CE}$ families, with family CE11 being the only one missing. The necrotrophic pea root pathogen Nectria haematococca has the most CEs (223). In general, Ascomycetes and Basidiomycetes have similar numbers of CEs, whereas Ascomycetes have more members of families CE3 $(\mathrm{P}<0.01)$ and CE5 $(\mathrm{P}<0.01)$ but fewer members of family CE16 $(\mathrm{P}<0.01)$ than Basidiomycetes (Figure 3). Families CE1 and CE10 are present in all the fungi examined and family CE4 is absent only in the nematophagous facultative parasitic fungus Arthrobotrys oligospora. In contrast, families CE6 and CE13 were found only in 3 and 2 fungi, respectively (Figure 2). Members of families CE1 and CE10 share the common activities of carboxylesterase and endo-1,4- $\beta$-xylanase. However, they have a great diversity in substrate specificity. For example, vast majority of CE10 enzymes act on non-carbohydrate substrates [2].

\section{Carbohydrate-binding modules (CBMs)}

CBMs are appended to carbohydrate active enzymes that degrade insoluble polysaccharides [26]. Fifty two of 65 CBM families were detected in fungi examined, with the most prevalent families being CBM21 and CBM23 (Figure 2). Ascomycetes tend to have more CBM18 $(\mathrm{P}<0.01)$ domains but fewer CBM12 $(\mathrm{P}<0.01)$, CBM13 $(\mathrm{P}<0.01)$ and CBM5 $(\mathrm{P}<0.01)$ domains than 

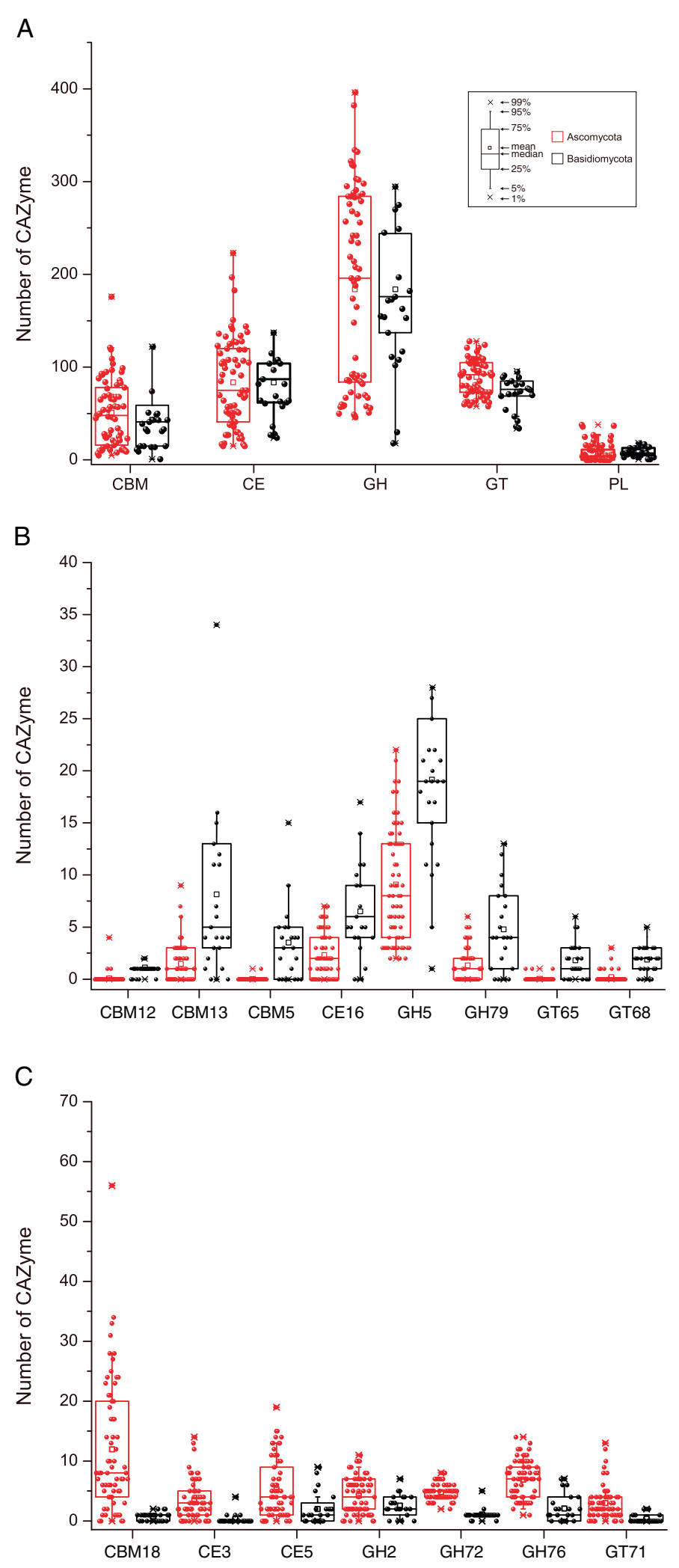

Figure 3 (See legend on next page.) 
(See figure on previous page.)

Figure 3 Different numbers of CAZymes between Ascomycetes and Basidiomycetes. (A) The number of CAZymes in each class and CBMs were plotted for Ascomycetes and Basidiomycetes. (B) The number of CAZymes in the families which were more abundant in Basidiomycetes than in Ascomycetes ( $t$ test, $\mathrm{P}<0.01$ ). (C) The number of CAZymes in the families which were more abundant in Ascomycetes than in Basidiomycetes ( $t$ test, $\mathrm{P}<0.01)$. See Figure 1 for abbreviations.

Basidiomycetes (Figure 3). Furthermore, many CBM families tend to be Ascomycota-specific, such as CBM16, CBM23, CBM27, and CBM37 (Table 1). Surprisingly, the facultative parasitic fungus $A$. oligospora has the most CBMs, particularly CBM1 modules with the putative cellulose-binding function [2].

\section{Plant cell wall degrading enzymes}

Plant cell walls are comprised mainly of pectins, celluloses, hemicelluloses, ligins, and other polysaccharides and proteins. We focus our detailed analysis on pectinases, cellulases, and hemicellulases because they are the major plant cell wall degrading enzymes in fungal pathogens. Although strictly speaking they are not cell wall degrading enzymes, cutinases are also included in this section because they are often produced in early infection stages by phytopathogenic fungi to breach the plant cuticle and function as important virulence factors in some fungi [27].

\section{Pectin degrading enzymes (Pectinases)}

Pectin can be broken down by pectin lyase, pectate lyase, pectin esterase, and polygalacturonase (PGA) [21,28]. These enzymes mainly fall into nine CAZyme families, including CE8, PL1, PL2, PL3, PL9, PL10, GH28, GH78, and GH88 [2,5,29]. Our results showed that fungi lack PL2 enzymes. Among 67 Ascomycetes examined, 31\% (21/67) lack enzymes belonging to these 9 CAZyme families. In contrast, the only one basidiomycete lacks any of them is Malassezia globosa, which is a facultative parasitic fungus causing dandruff on human skin. In lower fungi, only the saprophytic chytrid Allomyces macrogynus has pectinases. Interestingly, many vascular wilt and root pathogens, such as Verticillium albo-atrum, Verticillium dahlia, N. haematococca, and Fusarium oxysporum, tend to have more pectinases, which may be related to the blockage or collapse of vascular bundles during disease development.

Polygalacturonases (family GH28) play a critical role in pectin degradation in fungal pathogens. Several fungi, such as the necrotrophic white mold fungus Sclerotinia sclerotiorum, gray mold fungus Botryotinia fuckeliana, and opportunistic human pathogen Rhizopus oryzae, have an expanded family of PGAs (see Additional files 3, 4 and 5), suggesting that these fungi have high capacity of pectin degradation. In contrast, all the Saccharomycetes and Schizosaccharomycetes lack any PGA except the budding yeast Saccharomyces cerevisiae, which has a single PGA gene. Pectinesterases (family CE8) catalyze the de-esterification of pectin to pectate and methanol. Most fungi contain only a small number (no more than 8) of pectin esterases, which may play an auxiliary role in pectin breaking down.

\section{Lignocellulose degrading enzymes (lignocellulases)}

Lignocellulose is a tight complex formed by cellulose, hemicellulose, and lignin, and is the most abundant plant biomass on the planet. Lignocellulose degradation is a complex process involving the cooperation of heterogeneous groups of enzymes. For example, the thorough degradation of cellulose requires the collaboration of endoglucanase, cellobiohydrolase, and $\beta$-1, 4-glucosidase [30-32]. The GH class contributes the most catalytic enzymes to the degradation of lignocelluloses [4], such as cellulases in families GH1, GH3, GH5, GH45, and GH74 $[2,5,32]$, xylanases in families GH3, GH10, GH11, and GH39 [2,33]. At least $29 \mathrm{GH}$ families are known to be involved in the degradation of plant biomass $[2,5,29,32]$ (Table 2). Among them, families GH2, GH3, GH5, GH27, GH31, GH35, GH43, GH74, and GH78 tend to be more populated or abundant since that they are present in over a half of fungi examined and some of them are expanded in many fungi (Figure 2; Additional files 3, 4 and 5). Our results showed that all fungi examined have cellulose degrading enzymes such as members of family GH74. In contrast, only $38 \%$ of the bacterial genomes were reported to code cellulase genes [34].

GH3 family: Enzymes of this family are classified based on substrate specificity into $\beta$-D-glucosidases, $\alpha$ L-arabinofuranosidases, $\beta$-D-xylopyranosidases, and $\mathrm{N}$ acetyl- $\beta$-D-glucosaminidases [35]. The most common form is $\beta$-D-glucosidase $[5,29]$. Our results showed that GH3 enzymes were abundant in 89 of all fungi examined (Figure 2). Two necrotrophic fungi, $N$. haematococca and F. oxysporum, have more GH3 enzymes (38 and 32, respectively) than any other fungi. The tomato leaf mold fungus Cladosporium fulvum is the only biotrophic fungus with a larger number (20) of GH3 enzymes. Among the Chytridiomycetes, only the amphibian pathogen Spizellomyces punctatus has the GH3 member.

GH5 family: This is one of the largest GH families. It consists of a wide range of enzymes acting on different substrates [36], with the most common forms being exo-/ endo-glucanases and endomannanases [37,38]. Among all the GHs, members belonging to the GH5 family are the most common ones and they are present in all fungi 
Table 2 Known substrates (most common forms) of CAZymes

\begin{tabular}{|c|c|c|c|}
\hline Family & Substrates & Family & Substrates \\
\hline $\mathrm{GH} 1$ & CW( $\beta$-glycans) & $\mathrm{GH} 49$ & ESR (dextran) \\
\hline $\mathrm{GH} 10$ & PCW (hemicellulose) & GH5 & CW( $\beta$-glycans) \\
\hline GH105 & PCW (pectin) & GH51 & PCW(hemicellulose) \\
\hline $\mathrm{GH} 11$ & PCW (hemicellulose) & GH53 & PCW(hemicellulose) \\
\hline $\mathrm{GH} 115$ & PCW (hemicellulose) & GH54 & PCW (hemicellulose) \\
\hline $\mathrm{GH} 12$ & PCW(cellulose) & GH55 & FCW( $\beta-1,3$-glucan $)$ \\
\hline $\mathrm{GH} 125$ & PG(N-glycans) & GH6 & PCW (cellulose) \\
\hline $\mathrm{GH} 13$ & FCW + ESR(a-glucans) & $\mathrm{GH} 61^{*}$ & PCW (cellulose) \\
\hline $\mathrm{GH} 15$ & ESR (a-glucans) & GH62 & PCW (hemicellulose) \\
\hline $\mathrm{GH} 16$ & FCW( $\beta$-glycans) & GH63 & PG(N-glycans) \\
\hline $\mathrm{GH} 17$ & FCW( $\beta$-1,3-glucan) & GH64 & CW ( $\beta$-1,3-glucan) \\
\hline $\mathrm{GH} 18$ & FCW(chitin) & GH65 & ESR (trehalose) \\
\hline $\mathrm{GH} 2$ & CW( $\beta$-glycans) & GH67 & PCW (hemicellulose) \\
\hline $\mathrm{GH} 2 \mathrm{O}$ & FCW(chitin) & $\mathrm{GH} 7$ & PCW (cellulose) \\
\hline $\mathrm{GH} 23$ & $\mathrm{BPG}$ & GH71 & FCW( $\beta$-1,3-glucan) \\
\hline $\mathrm{GH} 24$ & $\mathrm{BPG}$ & $\mathrm{GH} 72$ & FCW( $\beta$-1,3-glucan) \\
\hline $\mathrm{GH} 25$ & $\mathrm{BPG}$ & $\mathrm{GH} 74$ & PCW (cellulose) \\
\hline $\mathrm{GH} 26$ & $\mathrm{BPG}$ & GH75 & FCW (chitin) \\
\hline $\mathrm{GH} 27$ & PCW (hemicellulose) & GH76 & FCW (chitin) \\
\hline $\mathrm{GH} 28$ & PCW (pectin) & $\mathrm{GH78}$ & PCW (pectin) \\
\hline $\mathrm{GH} 29$ & PCW (hemicellulose) & $\mathrm{GH} 8$ & $C W$ \\
\hline $\mathrm{GH} 3$ & CW ( $\beta$-glycans) & GH81 & FCW ( $\beta$-1,3-glucan) \\
\hline $\mathrm{GH} 30$ & FCW & GH85 & FCW \\
\hline $\mathrm{GH} 31$ & $P G+E S R+P C W($ hemicellulose) & GH88 & PCW (pectin) \\
\hline $\mathrm{GH} 32$ & ESR (sucrose/inulin) & GH89 & FCW \\
\hline $\mathrm{GH} 35$ & PCW (hemicellulose) & GH9 & $C W$ \\
\hline GH36 & PCW (hemicellulose) & GH93 & PCW (hemicellulose) \\
\hline $\mathrm{GH} 37$ & ESR (trehalose) & GH94 & PCW (cellulose) \\
\hline $\mathrm{GH} 38$ & PG (N-/O-glycans) & PL1 & PCW (pectin) \\
\hline $\mathrm{GH} 39$ & PCW (hemicellulose) & PL11 & PCW (pectin) \\
\hline $\mathrm{GH} 4$ & ESR & PL14 & BEPS \\
\hline $\mathrm{GH} 43$ & PCW (pectin + hemicellulose) & PL3 & PCW (pectin) \\
\hline GH45 & PCW (cellulose) & PL4 & PCW (pectin) \\
\hline $\mathrm{GH} 46$ & FCW(chitin) & PL7 & BEPS \\
\hline $\mathrm{GH} 47$ & PG(N-/O-glycans) & PL9 & PCW (pectin) \\
\hline
\end{tabular}

BEPS: Bacterial exopolysaccharides; BPG: Bacterial peptidoglycan; CW: Cell wall; ESR, energy storage and recovery; PCW: Plant cell wall; PG, protein glycosylation; FCW: Fungal cell wall.

*: Enzymes of GH61 family were not truly glycosidase, however, they are important to degrade lignocellulose in conjunction with cellulases [56], and were kept as GH in the CAZy classification [2].

examined, suggesting that these enzymes play important roles in fungal degradation of lignocellulose. In general, Basidiomycetes tend to have more GH5 enzymes than Ascomycetes. Interestingly, the biotrophic wheat rust fungi Puccinia graminis and Puccinia triticina tend to have more GH5 enzymes (28 and 27, respectively) than other fungi. Another biotrophic rust fungus Melampsora laricispopulina also has a large number (21) of GH5 enzymes. Rhodotorula glutinis, a saprophytic basidiomycete, is the only fungus with a single GH5 member.

GH10 and GH11 families: Enzymes of families GH10 and GH11 both display endoxylanase activities [2,39] but GH10 enzymes have higher substrate specificity than those of family GH11 [38]. Our results showed that 52 and 41 fungi have GH10 and GH11 enzymes, respectively, 42 of 94 fungi examined lack members belonging to these two families, including all entomopathogenic fungi.

GH51 and GH54 families: Enzymes of families GH51 and GH54 mainly decompose hemicelluloses such as arabinoxylan, arabinogalactan, and L-arabinan $[2,5,40]$. It was reported that fungal $\alpha$-arabinofuranosidases are mainly found in $\mathrm{GH}$ families 51 and 54 [38]. Our results showed that over half of the fungi examined lack either GH51 or GH54 enzymes, and 40 fungi lack any member of these two families (Additional files 3, 4 and 5). Most fungi examined have no more than three GH51 enzymes. On the other hand, the facultative parasitic fungus Penicillium marneffei tends to have the most GH54 (4) enzymes.

GH55, GH64, and GH81 families: Enzymes of families GH55, GH64, and GH81 display $\beta$-1,3-glucanase activities $[2,41]$. Their known substrates are mainly the fungal cell wall, which is enriched by $\beta$-1,3-glucan $[12,41]$. Callose is also a polysaccharide of $\beta-1,3$-glucan in plant cell wall. It is involved in the plant defense responses during interaction with pathogenic fungi [11]. Hence, we also investigated the variety of enzymes belonging to these three families among plant pathogenic fungi. Our results showed that family GH55 and GH81 enzymes showed no obvious variety among plant pathogenic fungi. Five out of six biotrophic fungi lack any GH64 member, whereas only two necrotrophic and one hemibiotrophic fungi lack any. Interestingly, the hemibiotrophic fungus Moniliophthora perniciosa lacks any member of these three families, distinctly deviating from other hemibiotrophic fungi.

\section{Cutinases}

Cutin is composed of hydroxy and hydroxyepoxy fatty acids. Cutinases (family CE5) catalyze the cleavage of ester bonds of cutin to release cutin monomers. Among the 94 fungi analyzed, 77 of them have cutinases (Figure 2). In 6 lower fungi belonging to Zygomycota and Chytridiomycota, only the zygomycete $R$. oryzae has no cutinase. Interestingly, the necrotrophic fungus Fomitiporia mediterranea lacks any cutinase. The hemibiotrophic rice blast fungus Magnaporthe oryzae has 19 cutinases, which is more than any other fungus. In $M$. oryzae, at least one cutinase gene is known to be important for plant infection 
$[42,43]$. Both two necrotrophic fungi, Gaeumannomyces graminis and $V$. albo-atrum, have 15 cutinases. Interestingly, all biotrophic fungi have cutinases, and the biotrophic fungus Cladosporium fulvum has 11 cutinases, which is more than some necrotrophic and hemibiotrophic fungi.

\section{Comparing abundance of CAZymes among fungi}

The fungi examined in this study vary significantly in the number of CAZymes. For example, nineteen of them have more than 500 CAZymes, twenty-two fungi have fewer than 200 CAZymes. In general, Dothideomycetes and Sordariomycetes contain more CAZymes and Saccharomycetes and Schizosaccharomycetes have fewer (Figure 1). For instance, there are 730 and 125 CAZymes in F. oxysporum and Schizosaccharomyces cryophilus, respectively.

\section{Saprophytic fungi}

Based on the number of predicted CAZymes, saprophytic fungi can be divided into two groups. The first group consists of 20 fungi that have more than 200 CAZymes from classes GH, CE and PL. However, they lost several CAZyme families, including families CE11, GH73, GH80, and GH82. Fungi of the second group, including 4 Schizosaccharomycetes, 2 Saccharomycetes, one eurotiomycete Uncinocarpus reesii, and one basidiomycete $R$. glutinis, have fewer than 200 CAZymes, which is fewer than the other saprophytes (Figure 1). Only $R$. glutinis of this group has PLs (Additional file 3). In contrast to the first group, the latter lost many CAZyme families of GHs and CEs, including families CE7, CE8, GH1, GH6, GH10, GH11, GH30, and GH79.

\section{Facultative parasitic fungi}

Facultative parasitic fungi normally live as saprobes but they are opportunistic pathogens of plants or animals. Similar to saprophytic fungi, facultative fungal pathogens can be divided into two groups based on the number and type of CAZymes (Figure 1). The ten fungi in the first group have more CAZymes than the second group and mainly are saprobes. Members of the second group have fewer than 230 CAZymes. Most of them lack PL enzymes and are facultative vertebrate pathogenic fungi, such as Candida species. In contrast to the first group, they lost most families of CAZymes related to the plant biomass degradation, such as families CE5, GH6, GH7, GH10, GH12, GH36, GH53, GH54, GH62, PL1, and PL3 (Additional file 4).

\section{Obligate parasitic fungi}

Obligate parasitic fungi depend on the presence of plant or animal hosts to complete their life cycle. In comparison with hemibiotrophic fungi, biotrophic fungi have the least CAZymes and necrotrophic fungi have the most CAZymes (Figure 1), although the numbers and variety of CAZymes in each group are diverse.

Biotrophic fungi derive nutrients from living tissues. Four of six biotrophic fungi analyzed are in phylum $\mathrm{Ba}$ sidiomycota, two are in phylum Ascomycota. In contrast to necrotrophic and hemibiotrophic fungi, biotrophic fungi lack GH6 enzymes, which are known to display endoglucanase and cellobiohydrolase activities [2] for plant cell wall degradation [5,29]. In general, biotrophic fungi tend to have fewer plant cell wall degrading enzymes than necrotrophic and hemibiotrophic fungi, such as enzymes of GH61, GH78, PL1 and PL3 (Figure 4). Furthermore, they also have fewer enzymes belonging to family GH76 and CBM1, CBM18, and CBM50 (Figure 4). Interestingly, CBM18 domains are present in various enzymes from families GH18, GH19, GH23, GH24, GH25, and GH73 [2]. Although it lacks experimental supports, the absence or reduction of these families may be correlated to their biotrophic lifestyles. Unlike other members of this group, the barley powdery mildew fungus B. graminis lacks any PL enzyme. C. fulvum differs from most other members of Mycosphaerellaceae by being a biotroph, while the others are hemibiotrophs or necrotrophs [44]. Interestingly, our results showed C. fulvum has significantly more CWDEs of families GH3, GH31, GH43, and PL3 than any other biotrophic fungi (Additional file 5). Similar to biotrophic pathogens, symbiotic fungi contain small number of CAZymes and also lack enzymes of family GH6. For example, Laccaria bicolor, a member of the Tricholomataceae family that can develop symbiotic associations with plant roots [45], contains a small number of CAZymes (Additional file 5). It may be beneficial to symbiotic fungi to contain fewer CAZymes for its symbiotic association with host plants.

Necrotrophic plant pathogens derive nutrients from dead host cells. Most of the necrotrophic fungi sequenced to date are from phyla Sordariomycetes, Dothideomycetes, and Leotiomycetes. The wood rotting fungus Dichomitus squalens is the only member of this group that lacks any PL1 enzymes which expanded in other necrotrophic fungi. G. graminis, M. poae, and S. sclerotiorum have fewer PLs than other fungi in this group (Figure 1; Additional file 5). Hemibiotrophic fungi have the initial biotrophic phase but switched to necrotrophic growth at late infection stages. In general, these fungi have more CAZymes than biotrophic fungi but similar to necrotrophic fungi in the number and diversity of CAZymes. M. perniciosa, the causal agent of the witches' broom disease of cocoa, contains only two cutinases (CE5), which is fewer than any other hemibiotrophic fungi. The diversity of CAZymes in fungi with different lifestyles suggests that the adaptation of fungal pathogens to different plant biomass and degrading capabilities. 

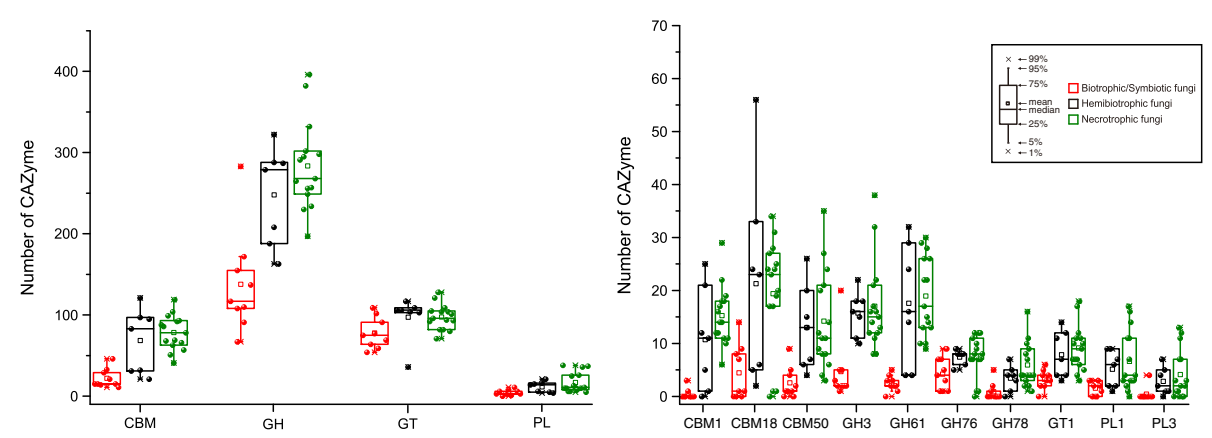

Figure 4 Comparison of CAZymes in different plant pathogenic fungi. (A) The number of CAZymes in each class and CBMs were plotted for biotrophic (red), hemibiotrophic (black), and necrotrophic (green) pathogens. (B) The number of CAZymes in the families that showed significant differences among biotrophic, hemibiotrophic, and necrotrophic pathogens. Differentiation was support by the $t$ test at the significant level with $P<0.01$. See Figure 1 for abbreviations.

\section{The diversity of CAZymes between monocot and dicot pathogens}

Some fungi can infect both dicots and monocots such as P. graminis, Melampsora larici-populin, and F. oxysporum. However, many fungi can only infect either dicots or monocots, such as $P$. teres [46]. Cell wall components of dicots and monocots are different, especially in the proportion of pectin and hemicellulose [6,21]. Activities of plant biomass degrading enzymes in some fungi also are known to have preference of biomass type of monocot or dicot plants [6]. To detect whether the CAZyme family diversity is correlated to the specificity of their hosts, we compared different pathogens that infect monocots or dicots. Because biotrophic fungi lack most of plant cell wall degrading enzymes, they were excluded in this analysis. In general, dicot pathogens have more pectinases belonging to families GH28 $(\mathrm{P}<0.01)$, GH88 $(\mathrm{P}<0.01)$, and GH105 $(\mathrm{P}<0.01)$ than fungi pathogenic to monocots (Figure 5), which agrees with the fact that cell walls of dicots are composed of higher levels of pectin than monocots [20]. Although the significance of the comparison between monocot and dicot pathogens with family PL1 and PL3 were not supported by the $t$ test, some dicot pathogens, such as $N$. haematococca, $V$. alboatrum, and $V$. dahlia, have more PL1 and PL3 enzymes than monocot pathogens.

Although dicot and monocot plants have different amounts of hemicelluloses in their cell wall, their pathogens have no significant differences in the diversity or number of enzymes related to the hemicellulose degrading. It should be noted that dicots and monocots have different levels of xylans and mannans in the primary cell wall but approximately the same level in the secondary cell wall [20]. The number of enzymes involved in cellulose degradation also has no significant differences between dicot and monocot pathogens, which agree with the fact that dicots and monocots are composed of similar levels of cutin and cellulose.
A

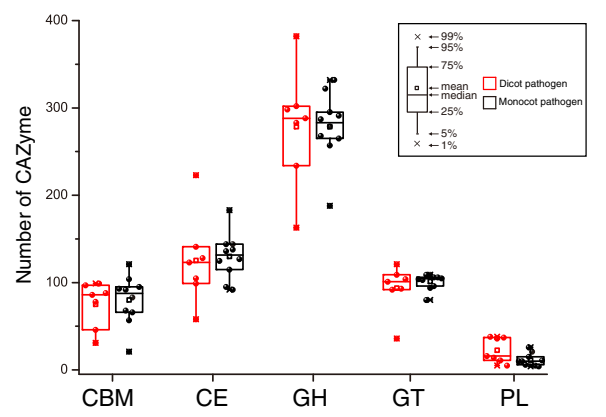

B

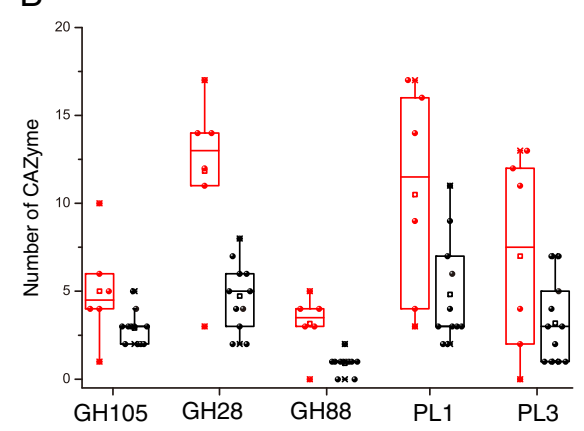

Figure 5 Comparison of CAZymes among fungi pathogenic to monocots and dicots. (A) The number of members in each CAZyme class and CBMs in the predicted proteomes were plotted for fungi that infect dicots (red dots) or monocots (black dots). (B) The number of CAZymes which showed obvious differentiation among fungi that infect dicots or monocots. Dicot pathogens have more pectinases from families $\mathrm{GH} 28(\mathrm{P}$ $<0.01)$, GH88 $(P<0.01)$ and $\mathrm{GH} 105(\mathrm{P}<0.01)$ than fungi pathogenic to monocots. Although the significance of the comparison was not supported by the $t$ test $(P>0.05)$, some dicot pathogens tend to have much more PL1 and PL3 enzymes than monocot pathogens. See Figure 1 for abbreviations. 


\section{Saprophytic fungi have fewer CAZymes than plant pathogenic fungi}

In general, saprophytic fungi are considered to produce a variety of CAZymes. Our results showed that saprophytic fungi have fewer CAZymes belonging to classes $\mathrm{CE}(\mathrm{P}<0.05), \mathrm{GH}(\mathrm{P}<0.05)$, and $\mathrm{PL}(\mathrm{P}<0.05)$, particularly families CE5 $(\mathrm{P}<0.01)$, GT1 $(\mathrm{P}<0.01)$, PL1 $(\mathrm{P}<0.01)$, and PL3 $(\mathrm{P}<0.01)$, than plant pathogenic fungi (Figure 6).

Interestingly, some fungi known for high capability of plant biomass degradation were found to contain fewer plant cell wall degrading enzymes in our analysis. For example, the opportunistic human pathogen $R$. oryzae has fewer lignocelluosic biomass degrading enzymes although it is known for its high degrading capacity [12]. The high level of gene expression and enzyme activity may contribute to these fungi's ability to degrade plant biomass.

\section{The presence of plant cell wall degrading enzymes in} fungi associated with animals

Some bacteria do not have a saprophytic lifestyle or cellulose degrading activity but contain cellulases belong to family GH6, GH12, and GH5 [34]. One example is the animal and human tuberculosis pathogen Mycobacterium tuberculosis, which has two cellulase genes belonging to family GH6 and GH12 but has no known relationship with plants [34]. Our results showed that some fungal parasites of vertebrates in group 2 of facultative parasitic fungi have lignocellulases although they can live only as saprobes or parasites to animals. For example, $M$. globosa is a lipid-dependent microorganism responsible for the onset of dandruff and other skin conditions in humans [47]. It has one member of family GH74, which is known to be involved in the degradation of plant celluloses $[5,29]$. Furthermore, it contains members of families GH105, GH31, GH43, GH5, and GH8, with which substrates are mainly plant lignocelluloses [5,29]. The amphibian pathogen Batrachochytrium dendrobatidis grows on amphibian skin [48] also has lignocellulases and is not known for association with plants.

Unlike bacteria, these fungi produce enzymes belong to families GH5 and GH3 but not families GH6 and GH12. Whereas GH5 enzymes mainly include endo/ exo-glucanase, endo-1,6-glucanase, mannanase, and xylanase, GH3 enzymes include $\beta$-glucosidase, glucan $\beta$ 1,3-glucosidase, cellodextrinase, and exo-1,3-1,4-glucanase. In contrast, GH6 enzymes include endoglucanase and cellobiohydrolyase and GH12 enzymes include endoglucanase, xyloglucan hydrolase, and $\beta-1,3-1,4$-glucanase. The predicted GH3 enzyme of $M$. globosa has the entire functional domain and conserved aspartic acid residue of the GFVISDW motif [35], suggesting that it is likely active. However, functional domains of some GH5 enzymes in $M$. globosa, such as 164657103, 164657414, and 164655644 , are truncated and unlikely to be active. Some cellulases are involved in cellulose biosynthesis in bacteria and plants $[49,50]$ but the fungal cell wall lacks cellulose. Thus, cellulase genes in animal pathogenic fungi may be remnants of ancestry genes, indicating that they may be evolved from plant pathogenic fungi.

\section{The expression profiles of CAZyme genes in Fusarium graminearum during plant infection}

To investigate whether genes coding CAZymes play important roles during plant infection, we analyzed the microarray data of the hemibiotrophic fungus F. graminearum from spike infection of barley (FG1) and wheat head (FG15), as well as conidia germination (FG7) downloaded from PLEXdb database (http://www.plexdb. org). All of the CAZyme genes (CEs, PLs, and GHs) identified in F. graminearum were expressed in these experiments. The expression profiles of these genes could be categorized into nine models by k-means clustering
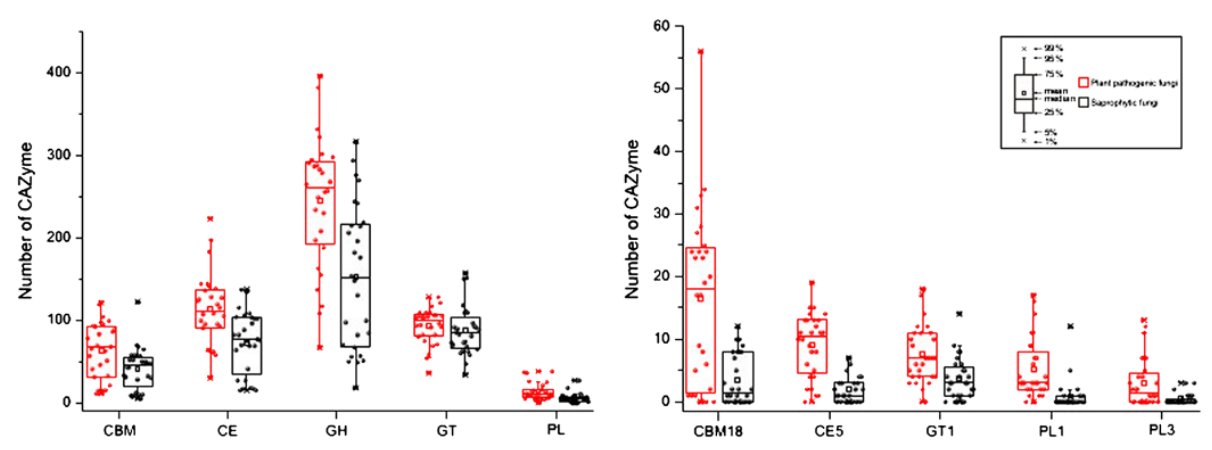

Figure 6 Comparison of CAZymes between saprophytic fungi and plant pathogenic fungi. (A) The number of members in each CAZyme class and CBM in the predicted proteomes were plotted for plant pathogenic fungi (red dots) and saprophytic fungi (black dots). (B) The number of CAZymes which showed obvious differentiation supported by $t$ test among plant pathogenic fungi and saprophytic fungi. 
algorithm implemented in program Mayday [51]. The expression profiles of spike infection of barley and wheat head were similar to each other but different from those of conidium germination. Most CAZyme genes were upregulated during plant infection (Additional file 6) but the majority of cluster 9 genes were down-regulated. These genes generally encode CEs and fungal cell wall decomposing enzymes, such as CEs FGSG_03012, FGSG_00784, and FGSG_11578 and GHs FGSG_03827, FGSG_04648, and FGSG_09648 (Additional file 7). In contrast to plant infection, conidium germination showed different gene expression models in cluster 1,2 , 5 , and 7. Genes in cluster 1 and 7 were down-regulated during conidium germination, indicating that they play less important roles in this process. Interestingly, genes in cluster 5 were up-regulated during germination but showed no obvious changes during wheat or barley infection, suggesting that they play more important roles in conidium germination than in plant infection.

\section{Evolution of fungal polysaccharide lyase family 1 (PL1)}

Family PL1 mainly displays activities of pectate lyases and pectin lyases, and is one of the largest families of PL class in fungi. Members in PL1 are important for plant infection and may be related to fungal virulence [18]. We found that saprophytic and pathogenic fungi differ significantly in the number of PL1 enzymes (Figure 6). To investigate their evolution in fungi, we reconstructed the phylogenetic tree for the PL1 enzymes (Figure 7 and Additional file 8). Many clades containing entries from different fungal taxa in the phylogenetic tree, suggesting that the last common fungal ancestor possessed numerous paralogous PL1 genes. The clades contain only one or some of fungal taxa and none of the taxa retains representatives of all ancestral paralogs, indicating that different subsets of ancestral paralogs may have been lost in certain fungal taxa during evolution. For example, Basidiomycetes may have lost most of the ancestral PL1 genes whereas Sordariomycetes have retained most of them (Figure 7). Furthermore, lineage or species-specific gene duplication (gain) events also have occurred within many fungal taxa, particularly in plant pathogens. For example, the Fusarium species, which are necrotrophic pathogens, contain many closely related paralogous PL1 genes, suggesting of the recent gene duplication and divergence events. In all, the phyletic distribution and

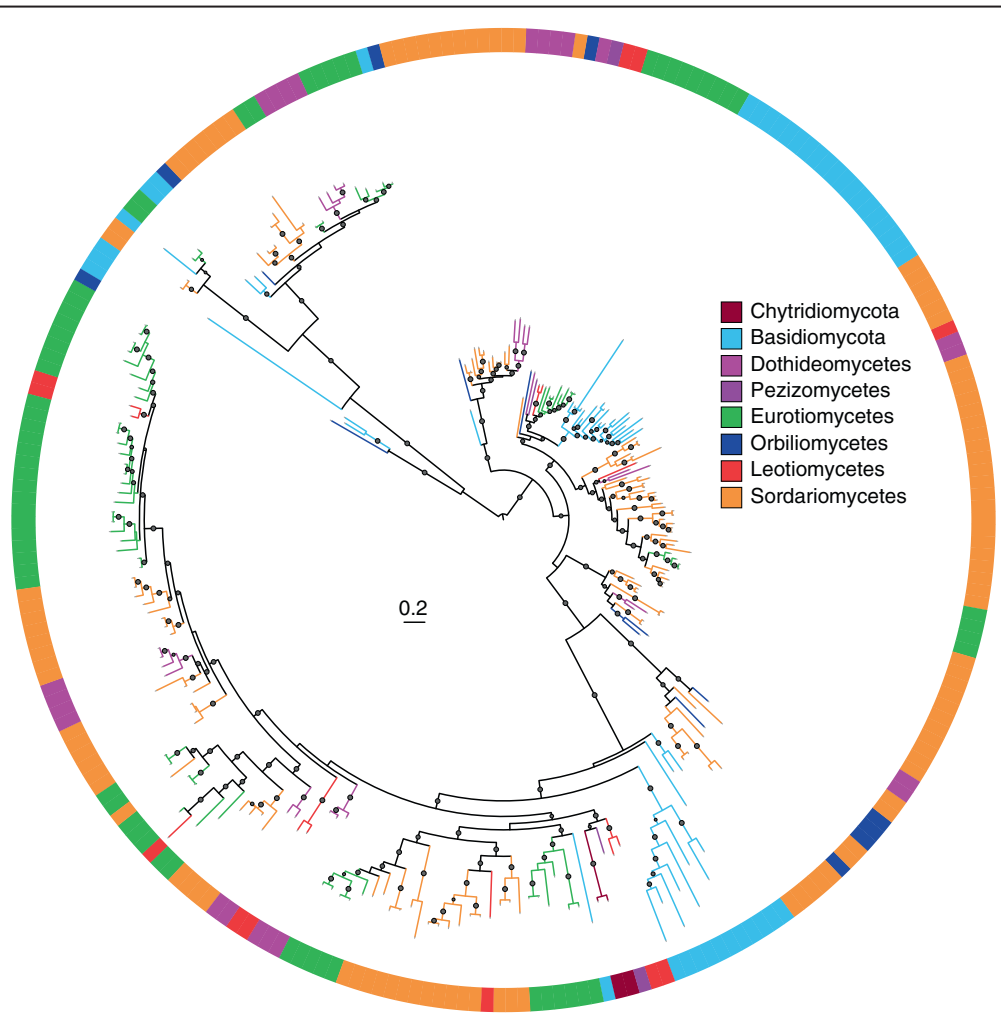

Figure 7 The maximum likelihood tree of family PL1. The phylogenetic tree was constructed with PhyML3.0 based on a multiple sequence alignment generated with PSI-Coffee [54]. The midpoint rooted base tree was drawn using Interactive Tree Of Life Version 2.1.1 (http://itol.embl. de/). The p-values of approximate likelihood ratios (SH-aLRT) plotted as circle marks on the branches (only p-values $>0.5$ are indicated) and circle size is proportional to the $p$-values. Scale bars correspond to 0.2 amino acid substitutions per site. A detailed version of this tree is found in Additional file 8. 
phylogenetic relationship of PL1 genes within different fungal taxa revealed a complex history of lineage-specific gene expansions and attritions which may be related to their nutritional strategies.

\section{Conclusions}

In conclusion, we systemically identified glycoside hydrolases, polysaccharide lyases, carbohydrate esterases, and glycosyltransferases, as well as carbohydrate-binding modules from predicted proteomes of 94 representative fungi belonging to Ascomycota, Basidiomycota, Chytridiomycota, and Zygomycota. Comparative analysis revealed that fungi exhibit tremendous diversity in the number and variety of CAZymes. Among them, some families of $\mathrm{GH}$ and $\mathrm{CE}$ are the most prevalent CAZymes that are present in all the fungi analyzed. Importantly, cellulases of some $\mathrm{GH}$ families are present in fungi that are not known to degrade celluloses. Our results also showed that plant pathogenic fungi, in general, contain more CAZymes than saprophytic, symbiotic, and animal pathogens. Among plant pathogens, biotrophic fungi have fewer CAZymes in comparison with necrotrophic and hemibiotrophic fungi. In addition, fungi infecting dicots contain more pectinases than fungi infecting monocots. Interestingly, several non-yeast saprophytic fungi, including $R$. oryzae, contain fewer CAZymes although they have high capacity of plant biomass degradation. Furthermore, analysis of the gene expression profiles of the wheat scab fungus $F$. graminearum revealed that most of the CAZyme genes were up-regulated during plant infection. Phylogenetic analysis of the PL1 family revealed a complex history of lineage-specific gene expansions and attritions. Results from this study provide insights into the variety and expansion of fungal CAZyme families and revealed the relationships of CAZyme size and diversity of fungi with their nutritional strategy and host specificity.

\section{Methods}

\section{Data collection and CAZyme annotation}

The predicted proteomes of 49 fungi were downloaded from Fungal Genome Initiative (FGI) site of Broad Institute (http://www.broadinstitute.org/science/projects/projects), 30 were obtained from GenBank of NCBI, 14 were downloaded from DOE Joint Genome Institute (JGI) site [52] (Three of them are unpublished: Cladonia grayi, Mucor circinelloides, and Phycomyces blakesleeanus), and 1 was downloaded from BluGen (http://www.blugen.org/) (Additional file 1).

We used the Hmmscan program in HMMER 3.0 package [53] to search each of fungal predicted proteomes with the family-specific HMM profiles of CAZymes downloaded from dbCAN database [22] as queries. The primary results were processed by the hmmscan-parser script supplied by the dbCAN.

\section{Cluster analysis of gene expression profiles of Fusarium graminearum CAZymes}

The expression data were downloaded from Plant Expression Database (PLEXdb) (http://www.plexdb.org/ index.php). For each experiment, three biological replicates were analyzed. The expression data of RMA treatment means for all probesets were used. The software Mayday 2.13 [51] was used to construct the k-means clustering with Pearson correlation distance measure. The CAZymes in GT class were not included in this analysis.

\section{Phylogenetic analysis}

Multiple alignments of protein sequences were constructed using PSI-Coffee [54] and the regions of large gap and ambiguous alignments were removed manually. Maximum likelihood (ML) phylogeny were estimated with PhyML3.0 assuming 8 categories of $\gamma$-distributed substitution rate and SPRs algorithms, based on amino acid sequence alignment and the best-fit model LG + F selected by ProtTest2.4 [55]. The reliability of internal branches was evaluated based on SH-like approximate likelihood ratios (aLRT) supports. The resulting alignment and phylogenetic tree have been deposited in treeBASE under URL (http://purl.org/phylo/treebase/phylows/study/TB2: S13822? $x$-access-code $=5$ adfa7c8af1e503811a8adfcec7f769f\& format=html).

\section{Statistical analysis}

We used the program OriginPro 8.5 (http://originlab. com/index.aspx?go=PRODUCTS/OriginPro) to generate statistical box charts. Independent samples $t$ tests were performed by the program SPSS Statistic 17.0 (www-01. ibm.com/software/analytics/spss/).

\section{Additional files}

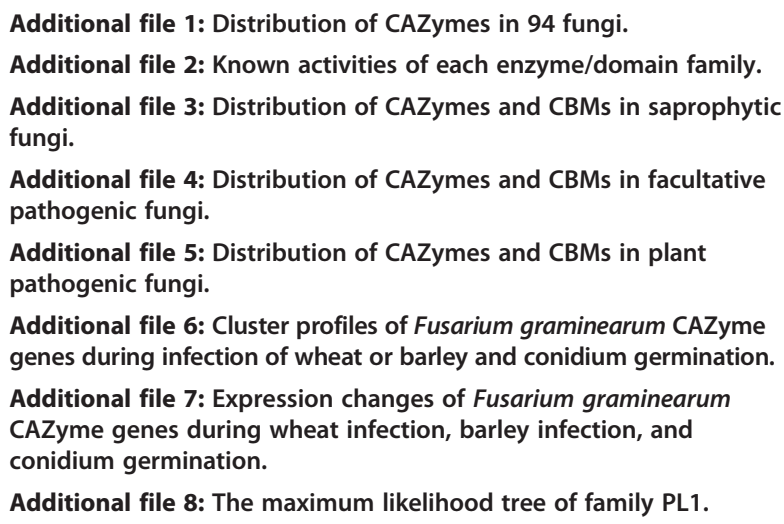

Additional file 8: The maximum likelihood tree of family PL1. 


\section{Abbreviations}

CA: Cutinase; CAZyme: Carbohydrate activity enzyme; CBM: Carbohydrate binding module; CE: Carbohydrate esterase; GH: Glycoside hydrolases; GT: Glycosyltransferase; CWDE: Cell wall degrading enzyme; PGA: Polygalacturonase; PL: Polysaccharide lyase.

\section{Competing interests}

The authors declare that they have no competing interests.

\section{Authors' contributions}

ZZ performed bioinformatic analyses, participated in the interpretation of the results and drafted the manuscript. HL designed and coordinated the study, participated in the bioinformatic analyses, in the interpretation of the results and in the writing of the manuscript. CW participated in the coordination of the study. JRX conceived the study, participated in the interpretation of the results and in the writing of the manuscript. All authors read, corrected and approved the final manuscript.

\section{Acknowledgements}

We thank Jun Guo from Northwest A\&F University for the supporting of fungal physiology knowledge and Lin An from Georgetown University for the data collection. We are grateful to the anonymous reviewers for their comments on the submitted manuscript. This work was supported by the National Major Project of Breeding for New Transgenic Organisms (2012ZX08009003) and the 973 program (Grant No. 2012CB114002) from the Ministry of Sciences and Technology, China. Genomes sequenced by JGl are supported by the Office of Science of the U.S. Department of Energy under Contract No. DE-AC02-05CH11231.

\section{Author details}

${ }^{1}$ NWAFU-PU Joint Research Center and State Key Laboratory of Crop Stress Biology for Arid Areas, College of Plant Protection, Northwest A\&F University, Yangling, Shaanxi 712100, China. ${ }^{2}$ Department of Botany and Plant Pathology, Purdue University, West Lafayette, IN 47907, USA.

Received: 14 August 2013 Accepted: 19 December 2013

Published: 3 January 2014

\section{References}

1. Zhao Z, Liu H, Wang C, Xu JR: Comparative analysis of fungal genomes reveals different plant cell wall degrading capacity in fungi. BMC Genomics 2013, 14(1):274

2. Cantarel BL, Coutinho PM, Rancurel C, Bernard T, Lombard V, Henrissat B: The Carbohydrate-Active EnZymes database (CAZy): an expert resource for Glycogenomics. Nucleic Acids Res 2009, 37(Database issue):D233-D238.

3. Ospina-Giraldo MD, Griffith JG, Laird EW, Mingora C: The CAZyome of Phytophthora spp: a comprehensive analysis of the gene complement coding for carbohydrate-active enzymes in species of the genus Phytophthora. BMC Genomics 2010, 11:525.

4. Murphy C, Powlowski J, Wu M, Butler G, Tsang A: Curation of characterized glycoside hydrolases of fungal origin. Database (Oxford) 2011. doi: 10.1093/database/bar020

5. Couturier M, Navarro D, Olive C, Chevret D, Haon M, Favel A, LesageMeessen L, Henrissat B, Coutinho PM, Berrin JG: Post-genomic analyses of fungal lignocellulosic biomass degradation reveal the unexpected potential of the plant pathogen Ustilago maydis. BMC Genomics 2012, 13:57.

6. King BC, Waxman KD, Nenni NV, Walker LP, Bergstrom GC, Gibson DM: Arsenal of plant cell wall degrading enzymes reflects host preference among plant pathogenic fungi. Biotechnol Biofuels 2011, 4:4.

7. Lu X, Sun J, Nimtz M, Wissing J, Zeng A-P, Rinas U: The intra- and extracellular proteome of Aspergillus niger growing on defined medium with xylose or maltose as carbon substrate. Microb Cell Fact 2010, 9(1):23.

8. Yuan X-L, Kaaij RM, Hondel CAMJJ, Punt PJ, Maarel MJEC, Dijkhuizen L, Ram AFJ: Aspergillus niger genome-wide analysis reveals a large number of novel alpha-glucan acting enzymes with unexpected expression profiles. Mol Genet Genomics 2008, 279(6):545-561.

9. Paper JM, Scott-Craig JS, Adhikari ND, Cuomo CA, Walton JD: Comparative proteomics of extracellular proteins in vitro and in planta from the pathogenic fungus Fusarium graminearum. Proteomics 2007, 7(17):3171-3183.
10. Mastronunzio JE, Tisa LS, Normand P, Benson DR: Comparative secretome analysis suggests low plant cell wall degrading capacity in Frankia symbionts. BMC Genomics 2008, 9(1):47.

11. Brown NA, Antoniw J, Hammond-Kosack KE: The predicted secretome of the plant pathogenic fungus Fusarium graminearum: a refined comparative analysis. PLoS One 2012, 7(4):e33731.

12. Battaglia E, Benoit I, van den Brink J, Wiebenga A, Coutinho PM, Henrissat B, de Vries RP: Carbohydrate-active enzymes from the zygomycete fungus Rhizopus oryzae: a highly specialized approach to carbohydrate degradation depicted at genome level. BMC Genomics 2011, 12:38.

13. Tian C, Beeson WT, lavarone AT, Sun J, Marletta MA, Cate JHD, Glass NL: Systems analysis of plant cell wall degradation by the model filamentous fungus Neurospora crassa. Proc Natl Acad Sci 2009, 106 (52):22157-22162.

14. Dashtban M, Schraft H, Syed TA, Qin W: Fungal biodegradation and enzymatic modification of lignin. Int J Biochem Mol Biol 2010, 1(1):36-50.

15. Floudas D, Binder M, Riley R, Barry K, Blanchette RA, Henrissat B, Martinez AT, Otillar R, Spatafora JW, Yadav JS, et al: The Paleozoic origin of enzymatic lignin decomposition reconstructed from 31 fungal genomes. Science 2012, 336(6089):1715-1719.

16. Douaiher MN, Nowak E, Durand R, Halama P, Reignault P: Correlative analysis of Mycosphaerella graminicola pathogenicity and cell walldegrading enzymes produced in vitro: the importance of xylanase and polygalacturonase. Plant Pathol 2007, 56(1):79-86.

17. Ferrari S, Galletti R, Pontiggia D, Manfredini C, Lionetti V, Bellincampi $D_{\text {, }}$ Cervone F, De Lorenzo G: Transgenic Expression of a Fungal endoPolygalacturonase Increases Plant Resistance to Pathogens and Reduces Auxin Sensitivity. Plant Physiol 2007, 146(2):669-681.

18. Kikot GE, Hours RA, Alconada TM: Contribution of cell wall degrading enzymes to pathogenesis of Fusarium graminearum: a review. J Basic Microbiol 2009, 49(3):231-241.

19. Skamnioti P, Furlong RF, Gurrl SJ: The fate of gene duplicates in the genomes of fungal pathogens. Commun Integr Biol 2008, 1(2):196-198.

20. Vogel J: Unique aspects of the grass cell wall. Curr Opin Plant Biol 2008, 11(3):301-307.

21. Lagaert S, Belien T, Volckaert G: Plant cell walls: Protecting the barrier from degradation by microbial enzymes. Semin Cell Dev Biol 2009, 20(9):1064-1073.

22. Yin Y, Mao X, Yang J, Chen $X$, Mao F, Xu Y: dbCAN: a web resource for automated carbohydrate-active enzyme annotation. Nucleic Acids Res 2012, 40(Web Server issue):W445-W451.

23. Tyler L, Bragg JN, Wu J, Yang X, Tuskan GA, Vogel JP: Annotation and comparative analysis of the glycoside hydrolase genes in Brachypodium distachyon. BMC Genomics 2010, 11:600.

24. Yip VL, Withers SG: Breakdown of oligosaccharides by the process of elimination. Curr Opin Chem Biol 2006, 10(2):147-155.

25. Biely P: Microbial carbohydrate esterases deacetylating plant polysaccharides. Biotechnol Adv 2012, 30(6):1575-1588.

26. Boraston AB, Bolam DN, Gilbert HJ, Davies GJ: Carbohydrate-binding modules: fine-tuning polysaccharide recognition. Biochem J 2004, 382(Pt 3):769-781.

27. Daviesa KA, Loronoa ID, Fosterb SJ, Lia D, Johnstonea K, Ashby AM: Evidence for a role of cutinase in pathogenicity of Pyrenopeziza brassicae on brassicas. Physiol Mol Plant Pathol 2000, 57(2):63-75.

28. Alghisi P, Favaron F: Pectin-degrading enzymes and plant-parasite interactions. Eur J Plant Pathol 1995, 101:365-375.

29. Martin F, Kohler A, Murat C, Balestrini R, Coutinho PM, Jaillon O, Montanini B, Morin E, Noel B, Percudani R, et al: Perigord black truffle genome uncovers evolutionary origins and mechanisms of symbiosis. Nature 2010, 464(7291):1033-1038.

30. Bubner P, Dohr J, Plank H, Mayrhofer C, Nidetzky B: Cellulases dig deep: in situ observation of the mesoscopic structural dynamics of enzymatic cellulose degradation. J Biol Chem 2011, 287(4):2759-2765.

31. Aro N, Pakula T, Penttila M: Transcriptional regulation of plant cell wall degradation by filamentous fungi. FEMS Microbiol Rev 2005, 29(4):719-739.

32. Li DC, Li AN, Papageorgiou AC: Cellulases from thermophilic fungi: recent insights and biotechnological potential. Enzyme Res 2011, 2011:308730.

33. Shallom D, Leon M, Bravman T, Ben-David A, Zaide G, Belakhov V, Shoham G, Schomburg D, Baasov T, Shoham Y: Biochemical characterization and identification of the catalytic residues of a family 43 beta-D-xylosidase from Geobacillus stearothermophilus T-6. Biochemistry 2005, 44(1):387-397. 
34. Medie FM, Davies GJ, Drancourt M, Henrissat B: Genome analyses highlight the different biological roles of cellulases. Nat Rev Microbio/ 2012, 10(3):227-234.

35. Harvey AJ, Hrmova M, De Gori R, Varghese JN, Fincher GB: Comparative modeling of the three-dimensional structures of family 3 glycoside hydrolases. Proteins 2000, 41(2):257-269.

36. Aspeborg H, Coutinho PM, Wang Y, Brumer H 3rd, Henrissat B: Evolution, substrate specificity and subfamily classification of glycoside hydrolase family 5 (GH5). BMC Evol Biol 2012, 12:186.

37. Dias FM, Vincent F, Pell G, Prates JA, Centeno MS, Tailford LE, Ferreira LM, Fontes CM, Davies GJ, Gilbert HJ: Insights into the molecular determinants of substrate specificity in glycoside hydrolase family 5 revealed by the crystal structure and kinetics of Cellvibrio mixtus mannosidase $5 \mathrm{~A}$. J Biol Chem 2004, 279(24):25517-25526.

38. van den Brink J, de Vries RP: Fungal enzyme sets for plant polysaccharide degradation. Appl Microbiol Biotechnol 2011, 91(6):1477-1492.

39. Ducros V, Charnock SJ, Derewenda U, Derewenda ZS, Dauter Z, Dupont C, Shareck F, Morosoli R, Kluepfel D, Davies GJ: Substrate specificity in glycoside hydrolase family 10 . Structural and kinetic analysis of the Streptomyces lividans xylanase 10A. J Biol Chem 2000, 275(30):23020-23026.

40. Paes G, Skov LK, O'Donohue MJ, Remond C, Kastrup JS, Gajhede M, Mirza O: The structure of the complex between a branched pentasaccharide and Thermobacillus xylanilyticus $\mathrm{GH}-51$ arabinofuranosidase reveals xylan-binding determinants and induced fit. Biochemistry 2008, 47(28):7441-7451.

41. Ishida T, Fushinobu S, Kawai R, Kitaoka M, Igarashi K, Samejima M: Crystal structure of glycoside hydrolase family $55 \beta$-1,3-glucanase from the basidiomycete Phanerochaete chrysosporium. J Biol Chem 2009, 284(15):10100-10109.

42. Skamnioti P, Gurr SJ: Magnaporthe grisea cutinase2 mediates appressorium differentiation and host penetration and is required for full virulence. The Plant Cell Online 2007, 19(8):2674-2689.

43. Skamnioti P, Gurr SJ: Cutinase and hydrophobin interplay: A herald for pathogenesis? Plant Signal Behav 2008, 3(4):248-250.

44. Grigoriev IV, Nordberg H, Shabalov I, Aerts A, Cantor M, Goodstein D, Kuo A, Minovitsky S, Nikitin R, Ohm RA, et al: The genome portal of the Department of Energy Joint Genome Institute. Nucleic Acids Res 2012, 40(Database issue):D26-D32.

45. Martin F, Aerts A, Ahren D, Brun A, Danchin EG, Duchaussoy F, Gibon J, Kohler A, Lindquist E, Pereda V, et al: The genome of Laccaria bicolor provides insights into mycorrhizal symbiosis. Nature 2008, 452(7183):88-92

46. Liu Z, Ellwood SR, Oliver RP, Friesen TL: Pyrenophora teres: profile of an increasingly damaging barley pathogen. Mol Plant Pathol 2011, 12(1):1-19.

47. Dawson TL: Malassezia globosa and restricta: Breakthrough Understanding of the Etiology and Treatment of Dandruff and Seborrheic Dermatitis through Whole-Genome Analysis. J Investig Dermatol Symp Proc 2007, 12(2):15-19.

48. Symonds EP, Trott DJ, Bird PS, Mills P: Growth characteristics and enzyme activity in Batrachochytrium dendrobatidis isolates. Mycopathologia 2008, 166(3):143-147.

49. Wong HC, Fear AL, Calhoon RD, Eichinger GH, Mayer R, Amikam D, Benziman M, Gelfand DH, Meade JH, Emerick AW, et al: Genetic organization of the cellulose synthase operon in Acetobacter xylinum. Proc Natl Acad Sci U S A 1990, 87(20):8130-8134.

50. Nicol F, His I, Jauneau A, Vernhettes S, Canut H, Hofte H: A plasma membrane-bound putative endo-1,4-beta-D-glucanase is required for normal wall assembly and cell elongation in Arabidopsis. EMBO J 1998, 17(19):5563-5576.

51. Battke F, Symons S, Nieselt K: Mayday-integrative analytics for expression data. BMC Bioinformatics 2010, 11:121

52. Grigorieva IV, Cullenb D, Goodwinc SB, Hibbettd D, Jeffriesb TW, Kubiceke CP, Kuskef C, Magnusong JK, Martinh F, Spataforai JW, et al: Fueling the future with fungal genomics. Mycology 2011, 2(3):192-209.

53. Eddy SR: A new generation of homology search tools based on probabilistic inference. Genome Inform 2009, 23(1):205-211.

54. Di Tommaso P, Moretti S, Xenarios I, Orobitg M, Montanyola A, Chang JM, Taly JF, Notredame C: T-Coffee: a web server for the multiple sequence alignment of protein and RNA sequences using structural information and homology extension. Nucleic Acids Res 2011, 39(Web Server issue): W13-W17.

55. Abascal F, Zardoya R, Posada D: ProtTest: selection of best-fit models of protein evolution. Bioinformatics 2005, 21(9):2104-2105.

56. Langston JA, Shaghasi T, Abbate E, Xu F, Vlasenko E, Sweeney MD: Oxidoreductive cellulose depolymerization by the enzymes cellobiose dehydrogenase and glycoside hydrolase 61. Appl Environ Microbiol 2011, 77(19):7007-7015.

doi:10.1186/1471-2164-15-6

Cite this article as: Zhao et al:: Correction: Comparative analysis of fungal genomes reveals different plant cell wall degrading capacity in fungi. BMC Genomics 2013 15:6.

\section{Submit your next manuscript to BioMed Central and take full advantage of:}

- Convenient online submission

- Thorough peer review

- No space constraints or color figure charges

- Immediate publication on acceptance

- Inclusion in PubMed, CAS, Scopus and Google Scholar

- Research which is freely available for redistribution 